\section{Editorial: Sobre o direito de recusar citações indesejadas}

Recentemente, Silva e Vuong (2021) levantaram uma importante questão acerca do processo de citações de textos acadêmicos: os autores teriam direito de recusar citações que considerem indesejadas? Já antecipando a conclusão do texto, eles defendem que os autores devem ter o direito de recusar tais citações, apesar de o texto destacar que o exercício de tal direito é demasiadamente difícil de ser praticado nos termos atuais em que o sistema de recompensas acadêmicas é delineado. Segundo os autores, existem tanto limites práticos que impossibilitam que a recusa de citações seja efetivamente exercida, bem como limites culturais, já que recusar citações vai contra ao senso vigente de que o maior número de citações remete à maior visibilidade e prestígio (Merton, 1968).

Em situações normais, a grande parte dos pesquisadores entenderia que quanto maior o número de citações melhor. Partindo desse pressuposto, a questão de Silva e Vuong (2021) poderia passar despercebida, sendo até julgada como inútil ou irrelevante. Todavia, temos alguns problemas com esse pressuposto.

Em primeiro lugar, considera-se que todas as citações possuem o mesmo peso, independentemente do autor ou periódico que cita. Isso não é verdade, já que qualquer teoria razoável que se debruça sobre a compreensão de mecanismos de status e prestígio no sistema de comunicação científica (ex. De Nooy, 2002) levaria em consideração que algumas citações, ao invés de favorecer o reconhecimento dos autores, o deterioram.

Em termos conceituais, o prestígio de um autor apresenta uma relação de dualidade com as obras que o citam. Ao ponto que receber citações de autores, periódicos ou instituições de maior prestígio pesam mais favoravelmente para um autor que citações de menor prestígio. Em tal relação de dualidade, o mesmo é válido para as fontes citantes: artigos, autores e periódicos também são julgados pela qualidade daquilo que citam. Em termos empíricos, estudos que analisam de forma mais acurada o prestígio acadêmico buscam formas de ponderar o peso das fontes citantes no ranqueamento, usando inclusive medidas de centralidade como o PageRank (Yan \& Ding, 2011). Em tais medidas, são considerados, por exemplo, como autores mais centrais não aqueles que recebem mais citações diretas, mas sim aqueles que recebem citações de autores mais citados. 0 inverso também é verdadeiro: aqueles que recebem maior quantidade de citações de autores pouco centrais, ou seja, com poucas citações, perdem centralidade ou prestígio, ao invés de ganharem. Assim, tanto em termos conceituais como empíricos, o que se manifesta é que algumas citações têm o potencial de desmerecer o trabalho de autores de prestígio, sendo candidatas a questionamentos.

Em segundo lugar, há razões mais pontuais para não se dar crédito a algumas citações. Como bem evidenciam Silva e Vuong (2021), tais citações
Luciano Rossoni (iD,

Editor da RECADM

Universidade Federal de Uberlândia, Brasil

Irossoni@gmail.com 
podem ter como origem pesquisas não confiáveis, irrelevantes ou de baixa qualidade. Segundo os autores, tais citações indesejadas provavelmente podem ocorrer quando há:

1) Má conduta dos autores citantes: i) que adotaram práticas não éticas ou desonestas na pesquisa; ii) produziram informação ou dados falsos; iii) em razão do artigo citante ter sido retratado;

2) Problemas na representação da citação: i) que é equivocada, errônea ou distorcida; ii) que é irrelevante ou puramente cerimonial;

3) Desconfiança acerca do periódico: i) quando há dúvidas da sua qualidade; ii) quando ele se enquadra como predatório.

Cada um dos enquadramentos acima configura-se como característica suficiente para definir se uma citação é indesejada, mesmo que algumas delas não se desdobrem em atitudes desonestas. Mas, como bem destacaram Silva e Vuong (2021), todas elas tendem a se manifestar, em maior grau, em periódicos predatórios, cujo processo editorial é falho ou inexistente, sem rigor no processo de revisão. Nesses casos, é muito pouco provável que um autor que sinta que a sua citação está sendo mal usada consiga de fato sacar a sua citação. Entretanto, a maior vantagem dos sistemas que contabilizam citações com algum grau de confiabilidade (por exemplo, Clarivate, Scopus e Spell) é que eles removem periódicos predatórios, de forma que tais citações sejam quase que inexistentes. Claro que ainda estarão presentes em mecanismos de indexação genéricos como o Google Scholar, que reconhecidamente são menos precisos que os demais (MartínMartín, Orduna-Malea \& López-Cózar, 2018). Em tal base, também não há alternativa de um autor exercer qualquer direito de remover uma citação indesejada.

Há casos ainda de publicações que cometeram fraudes na condução da pesquisa ou foram fruto de plágio em revistas de qualidade reconhecida. Nesses casos, a publicação é retratada e tanto o artigo é sacado quanto todas as citações são removidas automaticamente. Isso iria ao encontro do desejo do autor que foi citado indevidamente. No entanto, nas demais condições, que não envolvem nem periódicos predatórios, nem artigos retratados, o que se fazer? Silva e Vuong (2021) arguem que é muito difícil de se exercer tal direito, apesar de ser um direito de fato.

Por um lado, minha experiência como pesquisador e editor me levaria a concordar que é difícil de operacionalizar a recusa das citações, pois isso implicaria em se criar um sistema global de validação das referências, cujos autores citados seriam avisados das citações recebidas, o que de fato já existe (ex. Google Scholar e Publons), sendo convidados a validar tais citações. Seria mais uma atividade para editores gerenciarem e autores monitorarem cujo benefício individual não seria tão evidente.

Por outro lado, existem hoje tantos sistemas automatizados de informação científica com funções correlatas, que nos avisam quando o artigo é compartilhado nas redes sociais (ex. Altmetric e PlumX), e até registram a contribuição individual dos autores (CRediT). Não seria muito desafiador, com a tecnologia atual, especialmente com a vastidão de 
dados registrados no CrossRef e no $O R C I D$, que tal sistema de validação de referências citadas fosse construído, de forma que pudesse ajudar a separar citações de má qualidade das de maior qualidade. Assumindo que tal distinção existe, Silva e Vuong (2021) se fundamentam em Vuong (2018) para dizer que eliminar citações indevidas pode aumentar a qualidade da ciência, reduzir seus custos e aumentar a confiança do público em seus resultados.

No entanto, o exercício de tal direito de recusar citações, nas condições atuais, poderia criar um verdadeiro monstro Leviatã cujas consequências poderiam ser muito danosas. Se cabe ao autor citado decidir quais citações merecem ser validadas ou recusadas, quais garantias se teria de que ele utilizou o seu direito de forma devida? Até que ponto ele não poderia usar seu direito para excluir citações que hipoteticamente reduzem o seu prestígio? Pior: autores não estariam inclinados a rejeitar citações de textos que criticam suas obras? Essas questões que remetem a conflitos de interesses explícitos e também são acompanhadas de uma série de vieses de seleção e citação, que inconscientemente poderiam comprometer ainda mais o sistema já assimétrico de reconhecimento acadêmico.

Tais vieses de citação, como bem apontam Silva e Vuong (2021), podem favorecer periódicos indexados e de maior impacto, selecionando, em maior grau, autores e artigos mais citados, bem como privilegiar artigos cujos métodos e resultados sejam condizentes com os desejos dos autores citados. Há distorções que podem desequilibrar ainda mais as diferenças de gênero nas citações, sem falar que lógicas colonialistas acadêmicas podem se manifestar com ainda mais força, ignorando qualquer citação que seja originada de autores e periódicos de países não centrais, como é o caso do Brasil.

Colocando-me no lugar de editor de um periódico brasileiro que publica em português, eu me pergunto se boa parte dos autores citados no periódico validariam as referências aos seus trabalhos na RECADM. Por desconhecimento da qualidade do periódico, pela falta de capacidade de leitura em nossa língua, ou até por puro preconceito e discriminação, eu duvido que tais citações seriam recomendadas. Então por mais que eu acredite que o direito de recusar citações indevidas seja válido, eu temo que um sistema de rejeição e checagem de citações tornaria o mundo da ciência ainda mais desigual. $E$ isso não é uma questão de mérito: tem a haver com processos sociais de estratificação social, em que autores de países periféricos não têm a mesma oportunidade de demonstrar a qualidade do seu trabalho, por mais capazes que sejam. Concluindo, apesar do direito individual de um autor recusar citações ser legítimo e eu concordar com tal direito, ele pode levar a um processo de higienização da ciência transformando-a num sistema autoritário, o que me faz refutar os meios possíveis de exercer tal direito. 


\section{Nesta Edição}

Os artigos desta edição, em suas diferentes vertentes, ressaltam fortemente as implicações da vida em sociedade e da existência humana como fatores que se manifestam no contexto das organizações. Seja por meio de manifestações que remetem a dimensões objetivadas, mesmo quando envolvam o mundo das ideias, como no primeiro texto desta edição, ou até mesmo por meio de práticas que se materializam em campos organizacionais e mercados, como nos segundo e terceiros textos, tanto o papel da sociedade, como os interesses dos seres humanos estão presentes. Os elementos subjetivados também remetem a esses dois fatores, em que os quatro últimos textos desta edição, por meio do uso de métodos qualitativos de investigação, põem em evidência como seres humanos, corpóreos e sensitivos como são, delineiam as organizações de acordo com seus próprios anseios em negociação com a sociedade. Todos eles, a meu ver, dão destaque a como é necessário compreender como as organizações e os mercados se estruturam, tendo como referência fatores sociais, culturais e demográficos. Se tais fatores não compõem o cerne da teoria das organizações, eles compõem todo o seu entorno, de forma que é impossível compreender um sem reconhecer o outro.

Assim, no primeiro artigo desta edição, "Henri Fayol na encruzilhada da terceira via: organização da grande corporação e conflito social na forja do ideário fayolista", Elcemir Paço Cunha busca delimitar os fatores fundamentais na origem do pensamento fayolista. O autor vai além das "afinidades eletivas" entre as ideias de Fayol e de seus contemporâneos, buscando estabelecer, por sua vez, relações de "afinidade" entre as ideias de Fayol e os interesses que se manifestavam na França durante o seu período mais ativo. Para tanto, realiza uma investigação teórico-histórica inserida no campo da sociologia do conhecimento, tendo como base o materialismo científico e cuja formação ideal está ativamente ligada a condições objetivas reais. A pesquisa conclui que o ideário fayolista é uma resposta ao desenvolvimento da grande corporação capitalista em meio à crise econômica do século XIX e ao aguçamento do conflito social durante todo o período entre 1893 e 1920.

No segundo artigo, "A influência da maturidade do campo institucional na legitimidade do empreendedor institucional varejista", os autores André Luiz Barbosa da Silva e Juracy Parente descrevem como o grau de maturidade institucional do polo varejista de rua pode influenciar na construção da legitimidade do empreendedor institucional. Segundo os autores, diferentemente do que o institucionalismo organizacional postula, a busca por uma construção da legitimidade pelos empreendedores institucionais não é capaz de tornar suas ações legítimas. Isso decorreu das características do campo pré-emergente que não apresentou um grau mínimo de institucionalização necessária para garantir a atuação integral do empreendedor institucional varejista no processo de revitalização. Desta forma, a pesquisa reforça que, além de apresentar comportamentos de empreendedores institucionais e possuir um projeto relevante em benefício dos atores, deve-se analisar antecipadamente a maturidade do campo e 
perfil dos atores para posteriormente delinear estratégias de construção de legitimidade.

Também focando no fenômeno do empreendedorismo, no terceiro artigo, Roberto Pessoa de Queiroz Falcão e Eduardo Picanço Cruz buscam no artigo "Configuração de mercados étnicos nas dimensões temporal e ambiental: um ensaio teórico sobre negócios de imigrantes brasileiros" analisar o fenômeno da configuração de mercados de produtos e serviços étnicos dentro das comunidades imigrantes brasileiras estabelecidas no exterior. Por meio de um ensaio teórico, são feitas considerações baseadas em achados de trabalhos anteriores, em evidências empíricas e observações dos autores a respeito das práticas de mercados étnicos no seio de comunidades brasileiras. O relato e a interpretação dos fatos históricos foram estruturados evidenciando as práticas de transações, práticas normativas e práticas representacionais, bem como a configuração de mercados étnicos no sentido temporal e ambiental.

Os próximos dois artigos manifestam a preocupação de relacionar os estudos organizacionais com processos que remetem ao ciclo de vida dos seres humanos que, por sua vez, requerem organizações com funções bem específicas para a sua manutenção e existência. Assim, no quarto artigo, denominado "Os usos de si no trabalho em um banco de leite humano: uma análise do ponto de vista da atividade", Stephania Mendes Demarchi, Mônica de Fatima Bianco e Luana Sodré da Silva Santos se ativeram em compreender os usos de si nas situações de trabalho de profissionais de enfermagem inseridas em um banco de leite humano. Por meio de uma abordagem qualitativa com observação participante por um período de 3 meses, em que quatorze entrevistas individuais semiestruturadas e um grupo de discussão foram realizados, a pesquisa mostrou como a ergologia contribui para a compreensão do trabalho nas organizações. Os usos de si dessas profissionais, permeadas por experiências, histórias e valores, estão presentes no contexto e produzem melhorias significativas no banco de leite humano, colocando em evidência como as profissionais se engajam no cuidar, visando fazer o que pensam ser o melhor para os outros.

Já no quinto artigo, de autoria de Jessica Syrio Callefi e Elisa Yoshie Ichikawa, intitulado "O cotidiano e a territorialização dos idosos em um asilo do Norte do Paraná", tem como objetivo compreender como o cotidiano impacta a territorialização dos idosos em um asilo. Foram discutidos elementos teóricos do cotidiano certeauniano e da territorialização, que são a base analítica para esta investigação. Por meio da observação participante e de entrevistas de história oral de vida, as autoras identificaram que, mesmo de forma quase invisível, os moradores do asilo se utilizam de diversas práticas, tais como estratégias, táticas e conveniências para territorializar o espaço que habitam. Tais práticas também estão relacionadas ao que já foi vivenciado por esses indivíduos no passado, especialmente a como lidaram com suas perdas e mudanças na vida.

Os últimos dois artigos desta edição focam no fenômeno do consumo, ambos por meio de pesquisas etnográficas e suas derivações, como a netnografia. Assim, no sexto artigo, "Significação do consumo em botecos cariocas: uma análise da experiência na Mureta da Urca", Fábio Francisco 
de Araujo, Thais Barreto Estrella e Karla Andréa Dulce Tonini se propõem em compreender o processo de construção de significados das práticas de consumo que emergem no contexto de bares e botecos a partir da articulação entre cultura e consumo. Por meio do método etnográfico, focam em investigar o Bar e Restaurante Urca, considerado Patrimônio Cultural da Cidade do Rio de Janeiro. Os resultados apontam que o processo de significação pelos diferentes indivíduos frequentadores extrapola a lógica prática e objetiva que poderiam nortear as motivações de escolha para o consumo dos produtos e serviços. Esse processo favoreceu uma análise mais aprofundada sobre a produção de sentidos a partir da "teia de significado" que decorre das práticas no espaço pesquisado: a Mureta da Urca.

Por fim, no sétimo e último artigo desta edição, "Convergência da tecnologia e a intenção de consumo no setor automobilístico: uma pesquisa netnográfica", Emilio José Montero Arruda Filho e Luis Augusto Molina Alexandroni buscam compreender se os fatores tecnológicos influenciam a intenção de consumo no mercado automobilístico brasileiro, quando mediados pelos valores percebidos do produto. Por meio de uma pesquisa netnográfica e com o auxílio de uma ferramenta de Big Data, os autores observaram que nas intenções de consumo estão presentes os valores hedônicos, utilitários e sociais, e que características como prazer em dirigir, apreciação por tecnologia, economia, racionalidade na decisão de compra, extensão da personalidade e afirmação da personalidade perante o grupo social se manifestam. Verificaram também a ocorrência da devoção ao produto e/ou fabricante representada por características como paixão, sonho de consumo e valorização dos diferenciais do automóvel. Ademais, observaram também a presença de categorias negativas relacionadas à motivação para o consumo, como o medo para consumir e a expectativa frustrada após a compra.

Como um docente que exerce papel de editor de um periódico acadêmico, quero ressaltar que, mesmo diante de todas as dificuldades que a nação vem enfrentando, e de milhares de vidas sendo ceifadas diariamente, professores e pesquisadores não cessaram suas atividades em momento algum. Tanto que o número de submissões de artigos vem se mantendo elevado. Ademais, apesar da fadiga que as múltiplas atividades que precisam ser conciliadas no regime de home office causam em professores e pesquisadores, o trabalho de avaliação também se manteve constante. Isso demonstra a seriedade que todos têm com o seu trabalho, não deixando à deriva o sistema de comunicação científica. Para a RECADM, é motivo de alívio o comprometimento dos envolvidos, pois há casos de importantes periódicos no Brasil pararem de ser editados devido às dificuldades ocasionadas não somente pela pandemia, mas especialmente devido ao desinvestimento da esfera pública na ciência. Infelizmente, neste momento, manter um periódico vivo é um ato de resistência.

Apesar da luta, desejamos uma excelente e prazerosa leitura,

\section{Luciano Rossoni}

Editor da RECADM 


\section{Referências}

De Nooy, W. (2002). The dynamics of artistic prestige. Poetics, 30(3), 147-167.

Martín-Martín, A., Orduna-Malea, E., \& López-Cózar, E. D. (2018). Coverage of highly-cited documents in Google Scholar, Web of Science, and Scopus: a multidisciplinary comparison. Scientometrics, 116(3), 2175-2188.

Merton, R. K. (1968). The Matthew effect in science: the reward and communication systems of science are considered. Science, 159(3810), 56-63.

Silva, J. A. T., \& Vuong, Q. H. (2021). The right to refuse unwanted citations: rethinking the culture of science around the citation. Scientometrics, 126, 5355-5360.

Vuong, Q. H. (2018). The (ir)rational consideration of the cost of science in transition economies. Nature Human Behaviour, 2(1), 5-5.

Yan, E., \& Ding, Y. (2011). Discovering author impact: a PageRank perspective. Information Processing \& Management, 47(1), 125-134. 